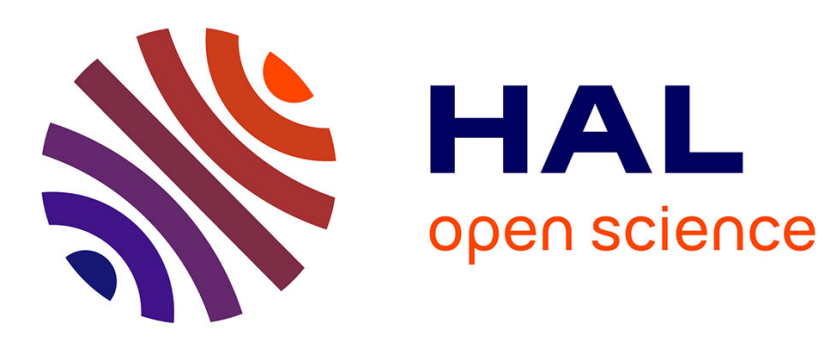

\title{
A novel FDSOI transistor-based uncooled microbolometer sensor for disruptive IRFPAs
}

Patrick Leduc, A. Aliane, Francis Balestra, Antoine Albouy

\section{To cite this version:}

Patrick Leduc, A. Aliane, Francis Balestra, Antoine Albouy. A novel FDSOI transistor-based uncooled microbolometer sensor for disruptive IRFPAs. OPTRO 2020, Jan 2020, paris, France. hal-02998409

\section{HAL Id: hal-02998409 \\ https://hal.science/hal-02998409}

Submitted on 3 Dec 2020

HAL is a multi-disciplinary open access archive for the deposit and dissemination of scientific research documents, whether they are published or not. The documents may come from teaching and research institutions in France or abroad, or from public or private research centers.
L'archive ouverte pluridisciplinaire HAL, est destinée au dépôt et à la diffusion de documents scientifiques de niveau recherche, publiés ou non, émanant des établissements d'enseignement et de recherche français ou étrangers, des laboratoires publics ou privés. 


\title{
A novel MOSFET-based uncooled sensor for disruptive IRFPAs
}

\author{
A.Albouy $^{(1)}$, J.J.Yon $^{(1)}$, P.Leduc ${ }^{(1)}$, G.Dumont $^{(1)}$, A.Aliane $^{(1)}$, F.Balestra $^{(2)}$ \\ (1): Univ. Grenoble Alpes, CEA, LETI, F38000 Grenoble, Univ. Grenoble Alpes, CEA, LETI/DOPT/SCIM/LI2T \\ 17 rue des Martyrs, 38054 Grenoble Cedex 9, France, Email: antoine.albouy@cea.fr \\ (2): Univ. Grenoble Alpes, CNRS, Grenoble INP, IMEP-LAHC,F-38000 Grenoble, 3, Parvis Louis Néel - CS 50257 \\ - 38016 Grenoble Cedex 1, Email: francis.balestra@grenoble-inp.fr
}

\begin{abstract}
:
Uncooled bolometer detecting in the long wave infrared (LWIR) is a key technology for a fast growing market supported by innovations in defense and security, automotive industry and Internet of Things (IOT). Thermistor materials whose resistance changes with temperature - like amorphous silicon (a-Si) or Vanadium Oxide (VOx) are commonly used as thermal sensitive element of uncooled bolometers. They are nevertheless not well suited for an ultimate cost reduction, as their fabrication requires a dedicated manufacturing line. One way to reduce the cost of production of this class of detectors is to aim at a bolometer integration scheme fully compatible with microelectronics industry. In this context, we propose a novel approach based on FDSOI (Fully Depleted Silicon-On- Insulator) MOS transistors as thermal sensitive element. Unlike thermistor technology, FDSOI transistors are realized on a standard CMOS line for high-throughput and lowcost manufacturing. Their performance as thermal sensors in subthreshold operation are besides higher than thermistors materials, with TCC (Temperature Coefficient of Current) in the range of $5.5-6 \% / \mathrm{K}$ against $2-2.5 \% / \mathrm{K}$ for the TCR (Temperature Coefficient of Resistance) of thermistor materials. From a technological point of view, the FPA final structure might be obtained by bonding these transistors from a first silicon wafer onto a second ROIC (Read Out Integrated Circuit) wafer thanks to a classical 3D integration process known as hybrid bonding (copper-copper and dielectric-dielectric direct bonding). This work consists in a first insight in the feasibility of the technology. It presents results obtained on FDSOI transistors that have been bonded on a second silicon wafer, thanks to a classical operation of $\mathrm{SiO}_{2}-\mathrm{SiO}_{2}$ molecular bonding. The substrate of origin (sensor wafer) of these
\end{abstract}

transistors has been etched away, and a second control gate has been formed on the backside of the transistors. Measurements comparing bonded and unbonded transistors are presented. Electrical parameters like I(V), low frequency noise and TCC (Temperature Coefficient of Current) measurements are discussed to compare transistors before and after bonding. Extraction of interface trap density has also been carried out in order to assess the impact of post-bonding technological steps on the interfaces of the FDSOI transistor. Results demonstrate that electrical performances are the same between transistors measured before and after bonding, including a same level of low frequency noise and a same TCC. Interface trap density extraction shows that interfaces before and after bonding are of the same quality. 


\section{INTRODUCTION}

InfraRed Focal Plane Array (IRFPA) is the most common way to design an infrared sensing device. It consists of an array of infrared detectors that is localized in the focal plane of a frontal lens [1].

Infrared detectors are usually sort into two classes: Quantum detectors and thermal detectors. Quantum detectors are high level performance detectors, but are required to be cooled at cryogenic temperature in order to lower the dark current. On the other hand, thermal detectors provide lower performances than quantum detectors but can operate at room temperature. Innovations in defense and security, automotive industry and Internet of Things impose a fast growing market and thus a necessity of reducing the cost of infrared detectors. Thermal detectors are therefore well suited for this aim, as they are cheaper and easier to integrate than quantum detectors.

Among thermal detectors, uncooled microbolometers detecting in the Long Wave InfraRed (LWIR, $8 \mu \mathrm{m}<\lambda<12 \mu \mathrm{m}$ ) stand as the leading infrared detector technology integrated in IRFPA devices [1]. Microbolometers are designed thanks to three elements [2]: An absorber absorbs the infrared flux, and heats up. This heat up is converted in an electrical signal by a thermal sensitive element. Finally, this electrical signal is collected by a Read Out Integrated Circuit (ROIC). The sensitive element and the absorber have to be highly thermally insulated with respect to the ROIC substrate. It is commonly realized by using adapted legs structure and by providing the bolometer IRFPA with a vacuum packaging. Therefore the final microbolometric pixel is suspended.

Thermistor materials like amorphous silicon a-Si [3] or vanadium oxide VOx [4] are commonly used as thermal sensitive element of uncooled microbolometers. As they are thermistor materials, it means that their electrical resistance $R$ changes with temperature. It allows us to define the figure of merit of these thermal transducers which is the Temperature Coefficient of Resistance (TCR), defined by Eq. 1

\section{Eq.1}

$$
T C R=\frac{1}{R} \frac{d R}{d T}
$$

State of the art TCR are in the range 2 to $2.5 \% / \mathrm{K}$, depending of the technology used. The most advanced pixel pitch of thermistors microbolometers are between $10 \mu \mathrm{m}$ [5] and $12 \mu \mathrm{m}$
[6]. State of the art Noise Equivalent Temperature Difference (NETD) of these microbolometers is around $50 \mathrm{mK}$ for a $12 \mu \mathrm{m}$ pixel pitch [6].

Despite these tremendous results there is still an aim of reducing the cost of infrared detectors in order to support innovations in industry. Indeed, thermistor materials fabrication requires a dedicated manufacturing line. They are therefore not well suited for an ultimate cost reduction. Then, one way of reducing the cost of the detector would be to obtain a bolometer integration scheme fully compatible with standard CMOS microelectronics processes.

Using CMOS devices as thermal sensitive element of microbolometers is a serious option to achieve this aim. Thus, groups have already propose PN junction [7-8]. Gitelman et al. [9] proposed a concept of bolometer where the thermal sensitive element is a Metal Oxide Semiconductor Field Effect Transistor (MOSFET) integrated on a Silicon-On-Insulator (SOI) film. Dry bulk micro machining is used to release the final structure, as the buried oxide (Box) of the FDSOI transistor is used as an etch stop layer. This technological process is nevertheless not suited for low pixel pitches, as the lower pixel pitch presented by Gitelman et al. is $45 \mu \mathrm{m} * 45 \mu \mathrm{m}$. There is therefore a necessity of going further this concept in order to achieve a most advanced pixel pitch, while benefiting from the CMOS standard technological steps in order to reduce the costs of infrared detectors.

This paper presents a novel structure of a FDSOI (Fully Depleted Silicon on Insulator) transistor as thermal sensitive element of an uncooled bolometer. The pixel architecture and the realization of a proof of concept are described, followed by the experimental results of this prototype.

\section{PIXEL ARCHITECTURE}

We propose a novel architecture for uncooled IRFPAs. This new architecture features an array of MOSFET transistors on a FDSOI silicon film to achieve the thermal sensitive element (of the IR sensor) in replacement of the usual thermistorbased transducer. This approach gives both higher thermal sensitivity (see results and discussion section) and higher manufacturability as it relies on very common and well-mastered silicon technologies.

Basically, this unique IRFPA technology arises 
from the vertical integration of two distinct silicon wafers, a first FDSOI-based wafer (i.e. the sensor wafer) where $2 \mathrm{D}$ arrays of MOSFET are implemented and a second CMOS-based wafer provided with readout integrated circuits (ROIC) in charge of operating the sensor arrays. (See Fig. 1.a). This vertical integration scheme gives rise to a higher IR flux collection when compared to other lateral constructions [10]. A second key advantage of proceeding with two separate wafers is the ability to use a manufacturing flow in a total independent fashion for achieving the sensor wafer and the ROIC wafer. Among different things, this gives the possibility to use a high temperature process to optimize the performance of the MOSFET sensor without negative impact on the thermal budget of the ROIC (processing temperatures above $400-450^{\circ} \mathrm{C}$ are prohibited to preserve the ROIC characteristics).

From a manufacturing point of view, the IRFPA final structure is obtained by transferring the sensor wafer on the ROIC wafer, thanks to a classical 3D integration process known as hybrid bonding. This operation proceeds by sticking together the sensor wafer and the ROIC wafer whose surfaces are each firstly prepared with mixed silicon dioxide $\left(\mathrm{SiO}_{2}\right)$ and copper $(\mathrm{Cu})$ areas and with special care to ensure a good flatness of both surfaces. The two wafers are aligned to put face-to-face the respective $\mathrm{Cu}$ areas. The alignment accuracy can reach 200nm [11]. When it is in contact, $\mathrm{SiO}_{2}$ areas first stick together even at ambient temperature thanks to molecular forces. Then a thermal annealing below $400^{\circ} \mathrm{C}$ allows the interdiffusion of the $\mathrm{Cu}$ areas leading to a monolithic $\mathrm{Cu}$ contact between the two wafers. Hence, an electrical connection between the MOSFET sensor and the ROIC is formed at the pixel level, using only CMOS compatible materials and low temperature processes.

Before bonding, the technology introduces a meandering legs structure located in a plane between the sensor wafer and the ROIC wafer (see Fig. 1.b). The purpose of this meandering line is to provide a good thermal insulation between the MOSFET-based transducer and the ROIC substrate. Since the legs are not in the same plane as the sensor, high optical fill factor close to $100 \%$ is expected. Moreover, this 3D stacking design allows to implement long insulation legs to enhance the thermal insulation and hence the sensitivity of the sensor. Integration of the legs is preferably chosen on the MOSFET wafer. They are imbedded between two $\mathrm{SiO}_{2}$ sacrificial layers to be spaced apart from the transistor itself except at locations where contacts to MOSFET source drain and gate terminals are provided. Both $\mathrm{SiO}_{2}$ sacrificial layers are etched with vapor hydrofluoric acid (HFv) at the end of the technology in order to release the MOSFET sensor in a suspended fashion.

After bonding, the substrate of origin of the sensor wafer is etched away by a mechanical grinding followed by a wet chemical etching till the buried oxide (BOX) layer of the SOI substrate. This leads to a very thin MOSFET arrangement with the benefit of achieving a microbolometer pixel with a low thermal time constant. Then after, a metallic IR absorber is formed on the backside of the transistor. As it is common, the metallic absorber can be made of a thin film of titanium nitride (TiN) that can additionally acts as a back gate of the transistor for a better electrostatic control of the MOSFET operation.

Finally, the bonded structure is processed in HFv to etch away all the sacrificial $\mathrm{SiO}_{2}$ layers leading to a free standing threefold structure featuring the ROIC, the meandering legs layer and the sensor body made of the MOSFET and of the absorber. Fig. 1 presents a 3D representation of the final pixel obtained by a Comsol Multiphysics simulation.

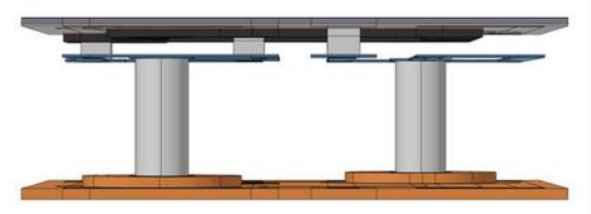

A

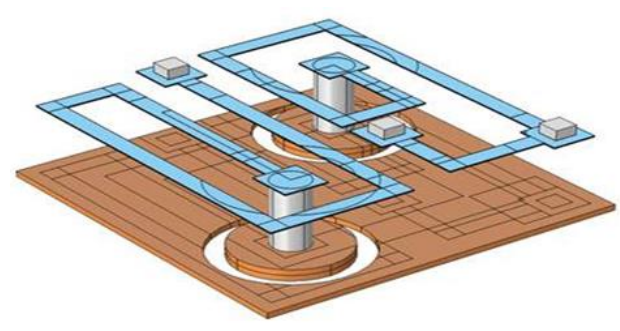

B

Figure 1: $3 D$ representation of the final pixel. The thermal sensitive element is a FDSOI transistor. Obtained thanks to a Comsol Multiphysics simulation.

\section{REALIZATION OF A PROOF OF CONCEPT}

In this paper we present a proof of concept of using a FDSOI transistor as thermal transducer. This work consists in a first insight in the feasibility of the technology. It presents results obtained on 
FDSOI transistors that have been bonded on a second silicon wafer, thanks to a classical operation of $\mathrm{SiO}_{2}-\mathrm{SiO}_{2}$ molecular bonding. The substrate of origin of these transistors (sensor wafer) has been etched away, and a second control gate has been formed on the backside of the transistors. Measurements comparing bonded and unbonded transistors are presented.

FDSOI transistors are fabricated in the $200 \mathrm{~mm}$ platform of CEA Leti's clean room. They follow a standard CMOS technological flow, which allows us to reach $300 \mathrm{~nm}$ minimum gate length. SOI substrates are provided by SOITEC and are realized by SmartCut technology [12]. SOI film thickness of $50 \mathrm{~nm}$ and Buried OXide (BOX) thickness of $145 \mathrm{~nm}$ are obtained. SOI film is $P$ type acceptor, and is low doped as the acceptor

\section{SOl substrate}

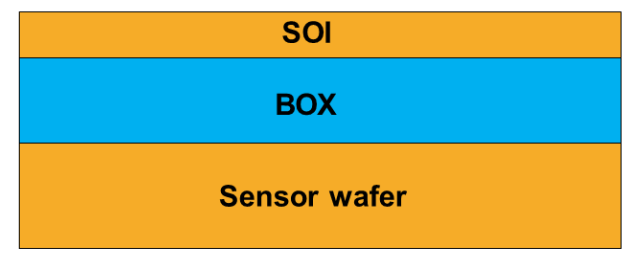

3. Source and drain zones

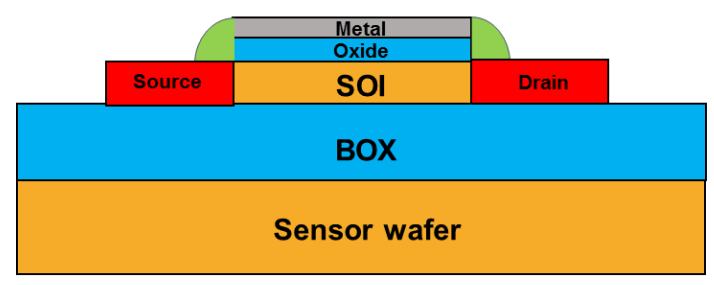

concentration is $\mathrm{Na}=1 \mathrm{e} 15 \mathrm{~cm}^{-3}$.

$\mathrm{SiO}_{2}$ gate oxide thickness of $9 \mathrm{~nm}$ is used. High-k and metal based gate are then used, with $\mathrm{HfO}_{2}$ dielectric ( $3 \mathrm{~nm}$ of thickness) and $\mathrm{TiN}$ as a metal gate, providing midgap workfunction. Source and drain zones are defined by donor ionic implantation, with LDD (Lightly Doped Drain) zones. Salicide technology is used to create ohmic contacts. Tungsten plugs then form the contact. PMD (Pre-Metal Dielectric) is deposited. Interconnexions and pads in aluminum are finally used to connect the transistor in order to perform the electrical characterizations. Fig. 2 gives a representation of the technological steps described before. Note that in Fig. 2 drain and gate are supposed shortened.

Figure 2: Technological steps from SOI substrate to transistor before bonding

Transistors are then bonded on a second passive silicon substrate, thanks to $\mathrm{SiO}_{2}-\mathrm{SiO}_{2}$ molecular bonding. The substrate of origin (sensor wafer) of the FDSOI transistor is etched away by a grinding step. The Buried Oxide is let intact, with a final thickness of $140 \mathrm{~nm}$. $20 \mathrm{~nm}$ of TEOS (TetraEthylOrthoSilicate) and $10 \mathrm{~nm}$ of TiN are then deposited in order to form the second gate. Contacts are reopened and interconnexion and pads are made once again with aluminum. Fig. 3 
gives a representation of the technological steps described before.

1. Transistor before bonding \& second silicon substrate

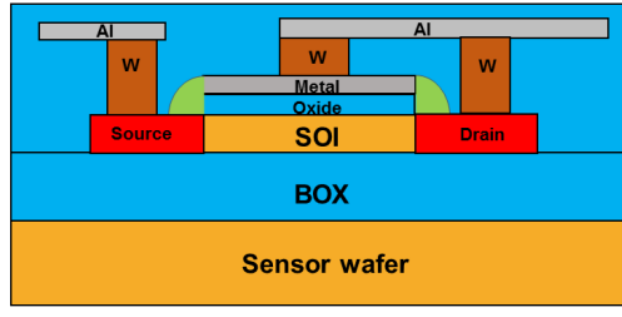

Second silicon substrate

3. Etching of the silicon substrate of origin \& deposition of TEOS

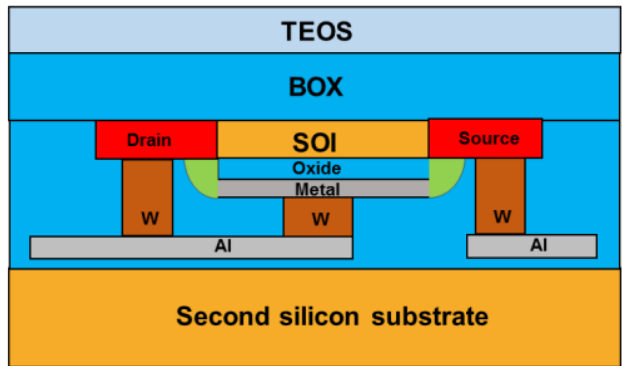

2. Transistor bonded on the second silicon substrate

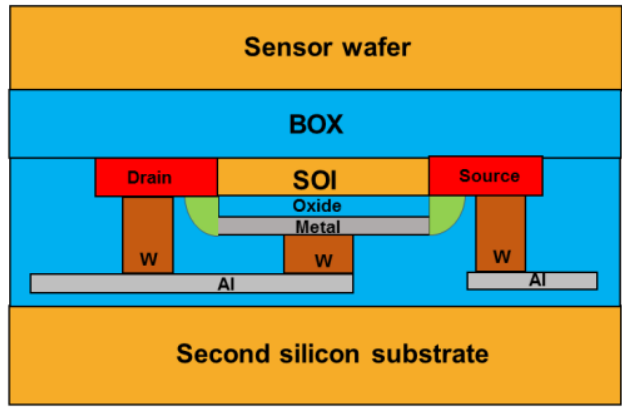

4. Constitution of the second gate, reopening of contacts and aluminum interconnexions

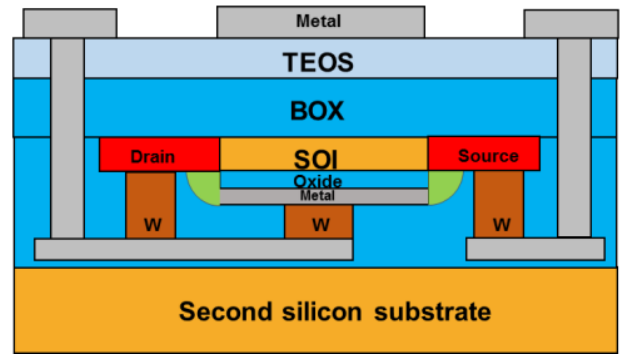

Figure 3: Technological steps from unbonded transistor to final bonded transistor

\section{EXPERIMENTAL PROTOCOLS}

Electrical characterizations of unbonded and bonded transistors are performed on-wafer with an analytical Cascade Microtech Summit probe system. A semiconductor parameter analyzer HP 4156 was used for collecting the DC IV data.

Electrical characteristics such as drain current $I_{d}$ vs gate voltage $V_{g}$ are measured, as well as transconductance $G_{m}$. From these electrical measurements threshold voltage $V_{t}$ and subthreshold slope $S$ are extracted. Interface trap density $D_{\text {it }}$ can be calculated (see discussion below) thanks to subthreshold slope measurements in order to assess the quality of the $\mathrm{Si} / \mathrm{SiO}_{2}$ interfaces. Electrical characteristics $\mathrm{I}_{\mathrm{d}}\left(\mathrm{V}_{\mathrm{g}}\right)$ are also measured with $\mathrm{V}_{\mathrm{b}}$ (second gate bias) as parameter in order to confirm that the second gate formed is electrically active after bonding. $V_{b}$ is applied by polarizing directly the chuck of the analytical probe system.

Electrical characteristics are also measured for several temperatures thanks to the thermochuck of the analytical probe system. To assess the FDSOI transistor as thermal sensitive element TCC is calculated. TCC is the Temperature Coefficient of Current, defined by Eq. 2:

Eq.2 $\quad T C C=\frac{1}{I d} \frac{d I d}{d T}$

It is the equivalent of the TCR of thermistors materials.

Once electrical characteristics are measured, wafers are cut in order to obtain unitary chips to allow measurements of low frequency noise. Unitary chips are stuck on a ceramic support and then placed into an isolated test chamber. Transistors are wire-bonded to get the contact. This isolated test chamber comprises a thermoelectric cooler allowing the possibility of changing the temperature, and can be operated in vacuum environment. For the measurements described in this paper vacuum in test chamber is not done.

Low frequency noise measurements are performed thanks to a low frequency noise measuring system 
which is constituted of a programmable bias amplifier. Spectral density is measured thanks to a Dynamic Signal Analyser (DSA) Agilent 35670A. Low frequency noise measuring system and Agilent 35670A are controlled by a PC with LabView. Low frequency noise measurements are used to extract the volume slow trap density per unit of energy $N_{t}$ in order to assess the impact of the after bonding process. Low frequency noise measurements are lead with $V_{g}$ and $V_{d}$ shortened in order to operate in saturation regime.

\section{RESULTS AND DISCUSSION}

Unbonded and bonded transistors are compared. Tab. 1 summarizes the transistors specifications used for measurements. Unbonded and bonded transistors were part of the same technological batch. In this paper only nMOSFET FDSOI

\begin{tabular}{|l|l|l|}
\hline & $\begin{array}{l}\text { Unbonded } \\
\text { transistor }\end{array}$ & $\begin{array}{l}\text { Bonded } \\
\text { transistor }\end{array}$ \\
\hline W (gate width) & $10 \mu \mathrm{m}$ & $10 \mu \mathrm{m}$ \\
\hline $\begin{array}{l}\mathrm{L} \text { (gate } \\
\text { length) }\end{array}$ & $0.5 \mu \mathrm{m}$ & $0.5 \mu \mathrm{m}$ \\
\hline $\begin{array}{l}\text { Tox (oxide } \\
\text { thickness) }\end{array}$ & $9 \mathrm{~nm}$ & $9 \mathrm{~nm}$ \\
\hline $\begin{array}{l}\text { Tbox (Buried } \\
\text { oxide } \\
\text { thickness) }\end{array}$ & $145 \mathrm{~nm}$ & $160 \mathrm{~nm}$ \\
\hline $\begin{array}{l}\text { Tsi (SOI film } \\
\text { thickness) }\end{array}$ & $50 \mathrm{~nm}$ & $50 \mathrm{~nm}$ \\
\hline Gate stack & $\mathrm{SiO}_{2} / \mathrm{HfO}_{2} / \mathrm{TiN}$ & $\mathrm{SiO}_{2} / \mathrm{HfO}_{2} / \mathrm{TiN}$ \\
\hline
\end{tabular}

transistors are tested.

Table 1: Specifications of the transistors studied in this paper.

\section{1. $I_{d}\left(V_{g}\right)$ characteristics}

Drain current $I_{d}$ vs gate voltage $V_{g}$ are measured in order to extract the threshold voltage $V_{t}$ and the subthreshold slope $S$ of transistors after and before bonding. $I_{d}\left(V_{g}\right)$ curves are measured at low drain voltage in order to operate in linear regime and thus to permit the extraction of $V_{t}$. Fig. 4 shows $I_{d}\left(V_{g}\right)$ at $V_{d}=10 m V$, in log scale.

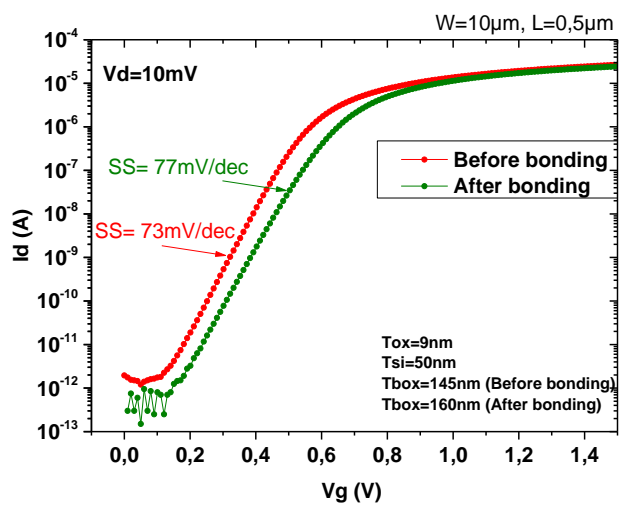

Figure 4: $I_{d}\left(V_{g}\right)$ in log scale for transistor before (red) and after bonding (green). $V_{d}=10 \mathrm{mV}$.

From these $I_{d}\left(V_{g}\right)$ characteristics, threshold voltage $V_{t}$ may be extracted with the Y-function method [14] defined by Eq. 3. Eq. 3 is valid only if $V_{d}$ is low, typically $10 \mathrm{mV}$, to operate in the linear regime.

Eq.3 $\quad Y(V g)=\frac{I d}{\sqrt{g m}}=\sqrt{\frac{W}{L} C_{o x} \mu_{0} V_{d}}(V g-V t)$

$\mathrm{C}_{\mathrm{ox}}$ is the capacity of the front oxide $\left(\mathrm{C}_{\mathrm{ox}}=\varepsilon_{\mathrm{ox}} / \mathrm{t}_{\mathrm{ox}}\right)$ and $\mu_{0}$ is the low field mobility. A linear regression is then applied to the linear part of the curve $Y$ function vs $V_{g}$ in order to extract $V_{t}$.

Subthreshold slope is defined by the inverse of the $\mathrm{Id}(\mathrm{Vg})$ slope in a log scale, as defined by Eq. 4, and is expressed in $\mathrm{mV} / \mathrm{dec}$.

Eq.4

$$
S=\left(\frac{d \log (I d)}{d V g}\right)^{-1}
$$

$S$ and $V_{t}$ parameters extracted from $\operatorname{ld}(\mathrm{Vg})$ characteristics are summarized in Tab. 2.

\begin{tabular}{|l|l|l|}
\hline & $\begin{array}{l}\text { Transistor } \\
\text { before bonding }\end{array}$ & $\begin{array}{l}\text { Transistor after } \\
\text { bonding }\end{array}$ \\
\hline $\mathrm{V}_{\mathrm{t}}$ & $0.51 \mathrm{~V}$ & $0.58 \mathrm{~V}$ \\
\hline $\mathrm{S}$ & $73 \mathrm{mV} / \mathrm{dec}$ & $77 \mathrm{mV} / \mathrm{dec}$ \\
\hline
\end{tabular}

Table 2: Results of the extraction of $V_{t}$ and $S$ for transistor before and after bonding.

Threshold voltage is increased of about $70 \mathrm{mV}$ for the transistor after bonding. One hypothesis is that this increase could be explained by the removal of the silicon substrate: In transistor before bonding, a depletion zone at the silicon substrate/BOX interface may influence the value of the threshold voltage. This depletion zone could be canceled with the removal of the silicon substrate.

Subthreshold slope between before and after 
bonding are in the same order which, as will be discussed later, is a synonym of a same value of interface trap density between the two situations.

\subsection{Validation of the electrical activity of the second gate}

Next, in order to validate that the second gate formed is electrically active, we measured $I_{d}\left(V_{g}\right)$ characteristics with second gate bias $V_{b}$ as parameter. Fig. 5 shows $I_{d}\left(V_{g}\right)$ characteristics for transistor bonded with $\mathrm{V}_{\mathrm{b}}$ as parameter. $\mathrm{V}_{\mathrm{b}}$ evolves from $-10 \mathrm{~V}$ to $10 \mathrm{~V}$ by steps of $1 \mathrm{~V}$.

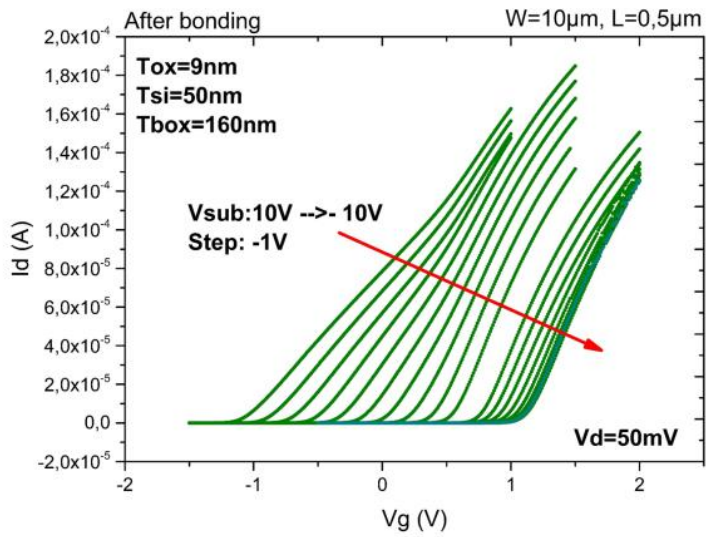

Figure 5: $I_{d}\left(V_{g}\right)$ with $V_{b}$ as parameter for transistor after bonding. $V_{b}$ varies from $-10 \mathrm{~V}$ to $10 \mathrm{~V}$ with a step of $1 \mathrm{~V}$.

$I_{d}\left(V_{g}\right)$ characteristics clearly evolves with $V_{b}$ bias. This is confirmed by the extraction of the threshold voltage $V_{t}$ as a function of $V_{b}$, as shown in Fig. 6.

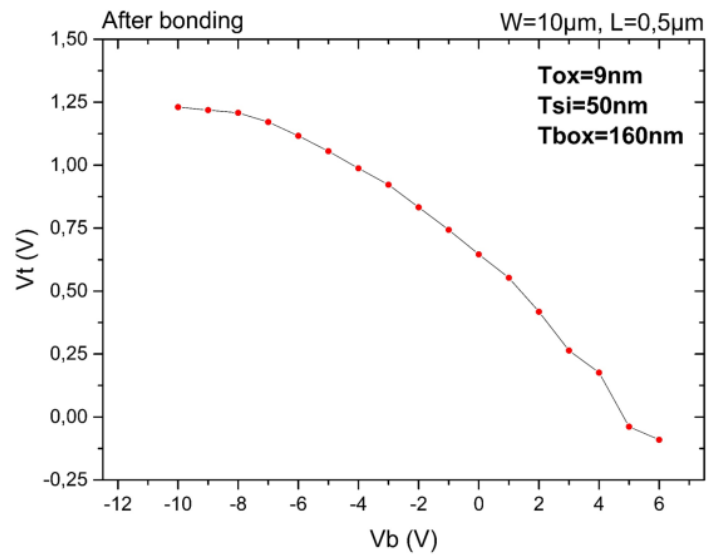

Figure 6: Threshold voltage of the bonded transistor versus $V_{b}$.
Threshold voltage versus $V_{b}$ curve follows the wellknown Lim model [15], which describes the coupling between the front and the back surface potential. A plateau is therefore obtained when $V_{b}$ is enough negative $\left(\mathrm{V}_{\mathrm{b}} \sim-8 \mathrm{~V}\right)$ to form an accumulation layer at the interface SOI/BOX and a linear decrease as SOI/BOX interface is progressively placed into depletion.

These results prove that the second gate formed is electrically active.

\subsection{Extraction of interface trap density}

Interface trap density $D_{\text {it }}$ is then extracted in order to assess the quality of the $\mathrm{Si} / \mathrm{SiO}_{2}$ interfaces in unbonded and bonded transistors.

Subthreshold method [16] is used in order to extract front $\left(D_{\text {itt }}\right)$ and back $\left(D_{\text {itb }}\right)$ interface trap density. This method is well adapted for $D_{\mathrm{it}}>1 \mathrm{e} 11 \mathrm{~cm}^{-2} \cdot \mathrm{eV}^{-1}$ but is rather imprecise for $D_{\mathrm{it}}<1 \mathrm{e} 11 \mathrm{~cm}^{-2} . \mathrm{eV}^{-1}$ [22].

Subthreshold method uses the capacitive model of the FDSOI transistor [16] in order to extract interface trap density $D_{i t}$. Fig. 7 shows the capacitive model of the FDSOI transistor when the back interface is depleted (left) and when the back interface is accumulated (right).
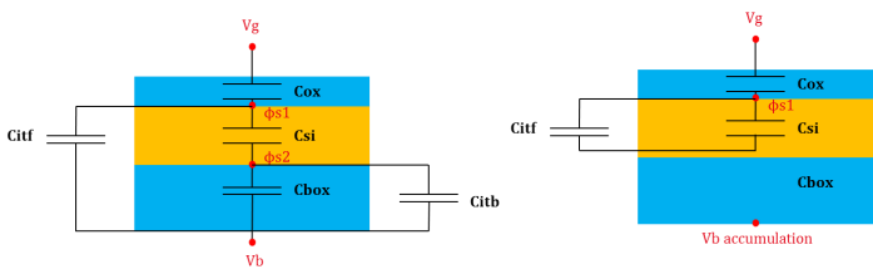

Figure 7: Capacitive model of the FDSOI transistor when the back interface is in accumulation (right) and in depletion (left).

When the back (front) interface is depleted, coupling between front and back interface occurs. As a result, the expression [16] of the front and back subthreshold are given by Eqs. 5-6. Subscripts $f$ and $b$ correspond respectively to front and back:

$$
\begin{aligned}
& \text { Eq.5 } \quad S S F=\frac{2.3 k T}{q}\left(1+\left(\frac{C i t f}{C o x}\right)+\frac{C b o x+C i t b}{C s i+C b o x+C i t b} \frac{C s i}{C o x}\right) \\
& \text { Eq.6 } \quad S S B=\frac{2.3 k T}{q}\left(1+\left(\frac{C i t b}{C b o x}\right)+\frac{C o x+C i t f}{C s i+C o x+C i t f} \frac{C s i}{C b o x}\right)
\end{aligned}
$$

$\mathrm{C}_{\text {itt, }, \mathrm{b}}$ are respectively the capacities of the front and back interface trap density $\left(C_{i t f, b}=q^{*} D_{i t f, b}\right), C_{o x}$ and $\mathrm{C}_{\text {box }}$ are respectively the capacities of the oxide of the front gate and of the buried oxide. $\left(\mathrm{C}_{\mathrm{ox}}=\right.$ $\left.\varepsilon_{o x} / t_{\text {ox }}, C_{\text {box }}=\varepsilon_{\text {ox }} / t_{\text {box }}\right) . C_{\text {si }}$ is the capacity of the SOI 
film $\left(\mathrm{C}_{\mathrm{si}}=\varepsilon_{\mathrm{si}} / \mathrm{t}_{\mathrm{si}}\right)$. Front (back) subthreshold slope when back (front) interface is in depletion depends directly of the back (front) interface quality via $D_{\text {itb }}$ $\left(D_{\text {itt }}\right)$.

On the contrary, when the back (front) interface is accumulated, front and back interfaces are decoupled and the front (back) subthreshold slope has the following expression [16]:$$
S S F=\frac{2.3 k T}{q}\left(1+\left(\frac{C i t f}{\operatorname{Cox}}\right)+\frac{C s i}{C o x}\right)
$$

Eq.8

$$
S S B=\frac{2.3 k T}{q}\left(1+\left(\frac{C i t b}{C b o x}\right)+\frac{C s i}{C b o x}\right)
$$

Thus, interface trap density of the front and back interfaces can be extracted from subthreshold swing measurements: A first measurement of the characteristics $I_{d}\left(V_{b}\right)$ with accumulation at the front interface gives $D_{\text {itb }}$ thanks to Eq. 8. Then, knowing the value of $D_{i t b}$, another $I_{d}\left(V_{g}\right)$ characteristics with back interface depleted (typically $V_{b}=V_{s}$ ) is measured, the front subthreshold slope is calculated and finally $D_{\text {itf }}$ is extracted thanks to Eq. 5.

This method was applied to unbonded and bonded

\begin{tabular}{|c|c|c|}
\hline & $\begin{array}{c}\text { Unbonded } \\
\text { transistor }\end{array}$ & $\begin{array}{c}\text { Transistor } \\
\text { bonded }\end{array}$ \\
\hline $\begin{array}{c}\mathrm{D}_{\text {itb }} \\
\left(\mathrm{cm}^{-2} \cdot \mathrm{eV}^{-1}\right)\end{array}$ & $5 \mathrm{e} 10$ & $5 \mathrm{e} 10$ \\
\hline $\begin{array}{c}\mathrm{D}_{\text {itf }} \\
\left(\mathrm{cm}^{-2} \cdot \mathrm{eV}^{-1}\right)\end{array}$ & $3.5 \mathrm{e} 11$ & $4.2 \mathrm{e} 11$ \\
\hline
\end{tabular}

transistors. Results are shown in Tab. 3.

Table 3: Extraction of $D_{\text {itb }}$ and $D_{\text {itt }}$ for unbonded and bonded transistors.

Values of $D_{\text {itb }}$ and $D_{\text {itf }}$ are very close between unbonded transistor and bonded transistor. It means that the technological operations after bonding described before did not degrade the quality of the interfaces of the FDSOI transistor. In particular, the operation of etching the original substrate did not deteriorate the quality of the back interface.

Value of $D_{\text {itb }}$ - around $5 \mathrm{e} 10 \mathrm{~cm}^{-2} \cdot \mathrm{eV}^{-1}$ - are typical values for SmartCut technology [11]. Values of $D_{\text {itt }}$ - around $3-4 \mathrm{e} 11 \mathrm{~cm}^{-2} \cdot \mathrm{eV}^{-1}$ - are state of the art values for $\mathrm{SiO}_{2} / \mathrm{HfO}_{2} / \mathrm{TiN}$ gate stack type [17].
Performances of FDSOI transistor as a thermometer are then discussed. TCC, defined by Eq. 2 above, is extracted by measuring $\operatorname{ld}(\mathrm{Vg})$ characteristics at $30^{\circ} \mathrm{C}$ and $35^{\circ} \mathrm{C}$. Fig. 8 shows TCC versus Id for unbonded and bonded transistors.

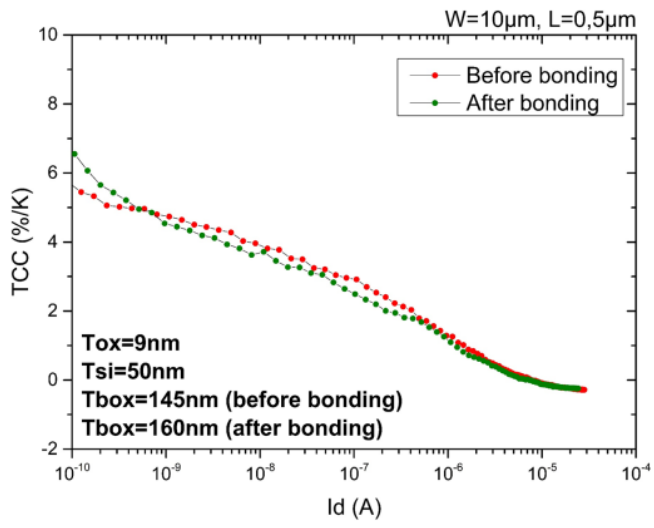

Figure 8: TCC versus Id for transistor before (red) and after (green) bonding.

TCC is not impacted by the bonding of the transistor. TCC of $4.7 \% / \mathrm{K}$ is obtained for a current $I_{d}=1 \mathrm{nA}$, confirming a higher temperature coefficient than thermistor materials for example. TCC is maximized in subthreshold operation, as diffusion regime is prominent.

\subsection{Noise measurements}

Finally, noise measurements are discussed. Fig. 9 shows the power spectral density $\mathrm{SI}_{d}$ normalized by $I_{d}{ }^{2}$ as a function of $I_{d}$ in log-log scale extracted for $\mathrm{f}=10 \mathrm{~Hz}$. These curves was obtained with $\mathrm{V}_{g}=\mathrm{V}_{d}$ so that transistors operate in saturation regime, for transistors $\mathrm{W} / \mathrm{L}=20$ before and after bonding.

\subsection{Thermal performances of transistors}




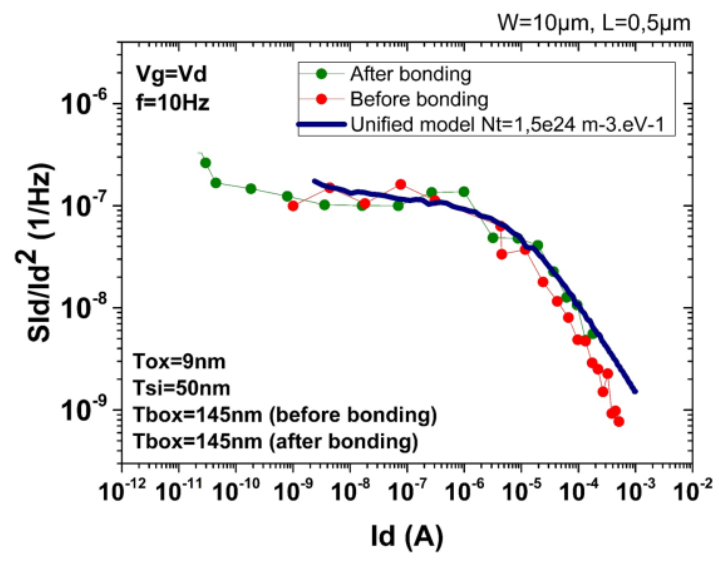

Figure 9: Normalized power spectral density versus $I_{d}$ for transistor before (red) and after bonding (green). Curves are fitted (blue) with the unified model. $\mathrm{N}_{t}=1.5 \mathrm{e} 24 \mathrm{~m}^{-3} . \mathrm{eV}^{1}$ is extracted.

Normalized power spectral density $S I_{d} / I_{d}{ }^{2}$ versus $I_{d}$ variations follow a classical McWorther model [18], which assumes that $1 / f$ noise in MOSFET is generated by number of carrier fluctuations: A plateau is present in subthreshold regime, while a decrease of $S I_{d} / l_{d}{ }^{2}$ with $I_{d}$ is present for inversion regime $\left(I_{d}>1 \mathrm{e}-6 \mu \mathrm{A}\right)$. These curves are fitted with the unified model [19], which combines number carrier fluctuations and correlated mobility fluctuations. Unified model gives a more detailed analysis than classical McWorther model. The unified model is particularly accurate for nMOS FDSOI devices [20]. The normalized power spectral density $S I_{d} / l_{d}{ }^{2}$ is define by Eq. 9 in the unified model [20]:

Eq.9 $\quad \frac{\operatorname{SId}(f)}{I d^{2}}=\frac{q^{2} \cdot k \cdot \cdot \cdot \cdot \cdot N t\left(E_{F}\right)}{W \cdot L \cdot C o x^{2} \cdot f}\left(\frac{g m}{I d}\right)^{2}\left(1+\alpha \cdot \mu_{e f f} \cdot \operatorname{Cox} \cdot \frac{I d}{g m}\right)^{2}$

Where $q$ is the electron charge, $k$ the Boltzmann constant, $T$ the temperature, $\lambda$ the tunneling constant in the $\mathrm{SiO}_{2}$ ( $\lambda$ is assumed equal to $0.1 \mathrm{~nm}$ [20]), $\mu_{\text {eff }}$ is the effective mobility and $\alpha$ the Coulomb scattering parameter ( $\alpha$ is chosen at $10^{\wedge} 4$ $\mathrm{Vs} / \mathrm{C}$ [20], since we measured nMOS devices).

The unified model is used to extract the interface trap density in the volume by unit of energy $N_{t}$ (in $\mathrm{m}^{-3} \cdot \mathrm{eV}^{-1}$ ), which represents the density of slow interface traps in the volume of the oxide localized at $0.1 \mathrm{~nm}$ of the $\mathrm{SiO}_{2} / \mathrm{Si}$ interface.

Fig. 9 shows that $1 / f$ noise level is equivalent for transistors before and after bonding, with in both cases a value of normalized $\mathrm{SI}_{\mathrm{d}} / \mathrm{l}_{\mathrm{d}}{ }^{2}$ close from $10^{-7}$ $1 / \mathrm{Hz}$ in subthreshold regime. $N_{t}$ in both situation is equal to $\mathrm{N}_{\mathrm{t}}=1.5 \mathrm{e} 24 \mathrm{~m}^{-3} \cdot \mathrm{eV}^{-1}$, which denotes that the technological steps after bonding did not degrade the quality of the interfaces. This result is coherent with interface trap density $D_{\text {it }}$ extraction presented before, as we obtain a same level of low frequency noise after the bonding. The value of $\mathrm{N}_{\mathrm{t}}=1 \mathrm{e} 24 \mathrm{~cm}^{-3} \cdot \mathrm{eV}^{-1}$ is state of the art $\mathrm{N}_{\mathrm{t}}$ value for $\mathrm{SiO}_{2} / \mathrm{HfO}_{2} / \mathrm{TiN}$ gate stack [21].

\section{CONCLUSION}

Results presented in this paper confirm the principle of using a FDSOI transistor as thermal sensitive element of an uncooled bolometer. Results demonstrate that electrical performances are the same between transistors before and after bonding, including a same level of the low frequency noise and a same TCC. Interface trap density extraction shows that interfaces before and after bonding have the same quality.

These results open the path to low cost uncooled microbolometers fully compatible with microelectronics industry because they are based on standard a CMOS technological flow.

\section{ACKNOWLEDGEMENT}

The authors would like to greatly thank our colleagues Claire Vialle, Valérie Goudon, Laurent Carle, Hacile Kaya, technicians and engineers from the silicon platform of the CEA Leti. 


\section{Bibliography}

[1] A.Rogalski et al. Challenges of small-pixel infrared detectors : a review. 2016. Rep. Prog. Phys. 79046501.

[2] J-J. Yon, E. Mottin, L. Biancardini, J-L. Tissot. 2003. Infrared Microbolometer Sensors and Their Application in Automotive Safety. [book auth.] W. Gessner J. Valldorf. Advanced Microsystems for Automotive Applications 2003.

[3] S. H. Black et al., "Uncooled detector development at Raytheon," 2011, vol. 8012, p. 80121A-80121A-12.

[4] J. L. Tissot et al., "High performance uncooled amorphous silicon VGA IRFPA with $17 \mu \mathrm{m}$ pixelpitch," in SPIE Defense, Security, and Sensing, 2010, p. 76600T-76600T.

[5] George D. Skidmore "Uncooled 10 4 m FPA development at DRS", Proc. SPIE 9819, Infrared Technology and Applications XLII, 981910 (20 May 2016)

[6] https://www.lynred.com/produit/atto320

[7] S. Eminoglu, M.Y. Tanrikulu, T. Akin. 2008. A Low-Cost $128 \times 128$ Uncooled Infrared Detector Array in CMOS Process. Journal of Microelectromechanical Systems. 2008, Vol. 17,1

[8] D. Takamuro et al. 2011. Development of new SOI diode structure for beyond $17 \mu \mathrm{m}$ pixel pitch
SOI diode uncooled IRFPAs. Proceedings of SPIE Vol. 8012, Infrared Technology and Applications XXXVII. 2011.

[9] L. Gitelman, S. Stolyarova, S. Bar-Lev, Z. Gutman, Y. Ochana, Y. Nemirovsky. 2009. CMOSSOI-MEMS Transistor for Uncooled IR Imaging. IEEE Transactions on Electron Devices. 2009, Vol. 56, 9.

[10] L. Dong, R. Yue, L. Liu. 2005. Fabrication and Characterization of Integrated Uncooled Infrared Sensor Arrays Using a-Si Thin-Film Transistors as Active Elements. Journal of Microelectromechanical Systems. 2005, Vol. 14, 5.

[11] I. Radu, D. Landru, G. Gaudin, G. Riou, C. Tempesta, F. Letertre, L. Di Cioccio, P. Gueguen, T.Signamarcheix, C. Euvrard, J.Dechamp, L. Clavelier, M. Sadaka. 2010. Recent developments of $\mathrm{Cu}-\mathrm{Cu}$ non-thermo compression bonding for wafer-to-wafer 3D stacking. IEEE International 3D Systems Integration Conference (3DIC). 2010.

[12] Jean-Pierre Colinge. SOI technology: Materials to VLSI,3rd edition. Springer Science, 2004.

[13] https://www.soitec.com/en/products/smart-cut

[14] Gérard Ghibaudo. New method for the extraction of mosfet parameters. Electronics Letters,24(9), 1988.

[15] H.K.Lim and J.G Fossum. Threshold voltage of thin-film silicon-on-insulator (soi) mosfet's. IEEE, 1983.

[16] Baquer Mazhari, Sorin Cristoloveanu, Dimitris E. loannou, and Anthony L. Caviglia. Properties of ultra-thin wafer-bonded silicon-on- insulator mosfet's. IEEE transactions on electron devices, 38(6), 1991.

[17] Mickael Cassé. HDR. Caractérisation électrique et modélisation du transport dans les dispositifs CMOS avancés. 2014.

[18] G.Reimbold. Modified 1/f trapping noise theory and experiments in mos transistors biased from weak to strong inversion. IEEE transactions on electron devices, 31(9), 1984.

[19] Hung, Ko, Hu, and CHENG. A unified model for the flicker noise in mosfet. IEEE transactions on electron devices, 37(3), 1990.

[20] E.Simoen et al. Low frequency noise in siliconon-insulator devices and technologies. Solid-State Electronics 51 (2007) 16-37. 
[21] E.Simoen et al. Low-Frequency Noise Behavior of SiO2-HfO2 Dual-Layer Gate Dielectric nMOSFETs With Different Interfacial Oxide

Thickness. IEEE transactions on electron devices, Vol.51, No.5, May 2004.

[22] M.Bawedin et al. Evalutation of interface trap density in advanced SOI MOSFETs. ECS

Transactions, 35 (5) 103-108 (2011). 